\title{
MEMBANGUN CITRA PENDIDIKAN KEJURUAN: MANFAAT DAN IMPLIKASINYA BAGI PERBAIKAN KUALITAS OUTPUT DAN OUTCOME
}

\author{
Ahmad Dardiri \\ Jurusan Pendidikan Teknik Bangunan, FT UM Malang \\ Jl. Semarang 5, Malang, Jawa Timur \\ dardiri@yahoo.com
}

\begin{abstract}
Abstrak: Di antara persoalan serius yang dihadapi Sekolah Menengah Kejuruan (SMK) saat ini adalah masih rendahnya persepsi citra SMK di tengah masyarakat. Rendahnya minat masuk SMK, rendahnya dukungan masyarakat pada penyelenggaraan SMK, rendahnya partisipasi industri pada pembelajaran SMK merukakan beberapa indikator dari rendahnya image tersebut. Hal tersebut tentu merupakan penghambat bagi upaya keberhasilan pembangunan pendidikan kejuruan. Sementara itu pendidikan kejuruan merupakan pendidikan yang berfokus pada penyiapan pemuda Indonesia untuk memasuki jenjang karir kehidupan sesuai kebutuhan dunia kerja. Oleh karena itu kondisi tersebut menjadi tantangan kepemimpinan kepala sekolah untuk melakukan pencitraan/promosi. Dari aspek-aspek filosofis, sosial, ekonomis dan ketenagakerjaan keberadaan pendidikan kejuruan memiliki justifikasi yang kuat untuk terus dikembangkan. Pencitraan memerlukan strategi pemasaran yang tepat mencakup posisioning, differensiation, dan branding keunggulan sekolah. Dengan citra yang baik diyakini dapat meningkatkan kualitas input, meningkatkan kepercayaan masyarakat industri, meningkatkan partisipasi serta kebanggaan masyarakat untuk mendukung pendidikan kejuruan, sehingga pada akhirnya dapat meningkatkan kualitas output dan outcome pendidikan kejuruan.
\end{abstract}

Kata kunci: Citra pendidikan kejuruan, kualitas output dan outcome

\begin{abstract}
One of the serious problems faced by Vocational School (SMK) is currently low image perception in the community. Low interest in enrollment, low public supports in class implementation, low industry participation in vocational learning are several indicators of the poor image. This is certainly an obstacle to the successful development of vocational education efforts. Meanwhile, vocational education is an education that focuses on preparing Indonesian youth to enter their world of work. Thus, the condition becomes a challenge to principals' leadership in establishing image/promoting. Vocational education development has strong justified philosophical, social, economic and employment aspects. The process of building image requires proper marketing strategies including positioning, differentiation, and school excellence branding. Good image is believed to improve quality of inputs, increase industrial public confidence, increase communities' participation and pride to support vocational education, which in turn can improve quality of outputs and outcomes of the vocational education.
\end{abstract}

Keywords: image of vocational education, quality of output and outcome

\section{PENDAHULUAN}

Telah lama pendidikan kejuruan di Indonesia mendapatkan citra negatif di tengah-tengah masyarakat. Hal tersebut tercermin dari rendahnya kualitas input pendidikan kejuruan, rendahnya dukungan industri terhadap penyelenggaraan pendidikan kejuruan, dan kurangnya sarana prasarana praktikum di pendidikan 
kejuruan, serta rendahnya tingkat sosial ekonomi siswa pendidikan kejuruan. Rerata Nilai Ebtanas Murni (NEM) input Sekolah Menengah Kejuruan (SMK) selama empat tahun terakhir (2005-2008) di Madang jauh lebih rendah dibanding NEM input Sekolah Menengah Atas (SMA) (http://www.malang.psb.online); di Banjarbaru kalimantan Selatan jumlah pendaftar lulusan SMP yang melanjutkan di SMK sedangkan 60\% mendaftar ke SMA (http://www.id.banjarbarukota.go.id). Tentu saja kondisi tersebut menjadi kendala dalam upaya meningkatkan kualitas pendidikan kejuruan.

Pandangan negatif terhadap pendidikan vokasi (vocational education and training/NET) tersebut tidak hanya terjadi di Indonesia tetapi juga di negara-negara lain. Paryono (2006: 1) melaporkan penelitian bahwa di negara-negara Asia Tenggara pendidikan kejuruan juga memiliki citra yang kurang baik. Dia menyebutkan "... most VTE programmes still suffer from the negative stigma attached to them. VTE is still perceived as an education for those from economically and academically disadvantaged only” (http://www.voced.edu.au/td/tnc_92.220) Pimpa (2007: 33-47) melaporkan hasil penelitiannya dalam pertemuan ilmiah internasional tanggal 25-29 November 2007 di Australia bahwa pendidikan kejuruan di Thailand juga memiliki citra negatif dan bukan menjadi pilihan untuk melanjutkan studi bagi pemuda-pemuda di negara tersebut (http://www.aare.edu.au/07pap/pin07613/pdf.). Di Australia dalam penyelenggaraan Training and Further Education (TAFE) magang industri juga dilaporkan bahwa pendidikan vokasi lebih banyak diikuti oleh siswa dari kalangan orang tua berpenghasilan rendah dan bekerja manual (Harris, Simon, \& Moore, 2005: 7-14).

Dari uraian tersebut jelas bahwa pendidikan kejuruan/vokasi menghadapi tantangan yang cukup berat yakni merubah citra negatif menjadi positif. Persoalannya antara lain: (1) mengapa masyarakat khususnya pemuda memiliki pandangan negatif terhadap pendidikan kejuruan?; (2) langkah-langkah apa yang telah dilakukan sekolah untuk merubah citra negatif pendidikan kejuruan menjadi positif?; (3) siapa yang harus melaksanakan perubahan tersebut?; (4) kenapa citra pendidikan harus dirubah?; dan (6) apa implikasinya bagi kepemimpinan kepala sekolah di lingkungan pendidikan kejuruan? 


\section{ANALISIS DAN PEMBAHASAN}

\section{Pengertian Pendidikan Kejuruan}

Pendidikan kejuruan adalah pendidikan yang mempersiapkan seseorang agar memiliki kemampuan bekerja pada satu kelompok pekerjaan atau satu bidang pekerjaan (Rupert Evans, 1925 dikutip Wardiman, 1998: 33). United States Conggres (1976 dalam Wardiman, 1998: 35) mendefinisikan pendidikan kejuruan adalah program pendidikan yang secara langsung berkaitan dengan penyiapan seseorang untuk satu pekerjaan tertentu atau untuk persiapan tambahan karir seseorang . Pendapat yang lain dikemukakan oleh Perkins (1998: 101-192) sebagai berikut.

Vocational education as organized educational programs offering a sequence of courses directly relate to preparing individuals for paid or unpaid employment in current. Programs include competency-based applied learning, which contributes to an individual's academic knowledge, higher order reasoning, problem solving skills, and the occupational-specific skills necessary for economic independence as productive and contributing member of society" (http://proquest.umi.com/pqdweb).

Pendapat Perkins tersebut menekankan bahwa isi program pendidikan kejuruan di organisasi guna menyiapkan individu untuk bekerja, yaitu dengan memberikan seperangkat kompetensi dasar yang meliputi keterampilan berpikir dan keterampilan fisik yang spesifik untuk bekerja, sehingga memberikan kontribusi ekonomi negara dan dalam kehidupannya di masyarakat.

Menurut Undang-undang Republik Indonesia Nomor 20 tahun 2003 tentang Sistem Pendidikan Nasional, pendidikan kejuruan merupakan pendidikan yang mempersiapkan peserta didik untuk dapat bekerja pada bidang tertentu. Dalam UU RI No. 20 tahun 2003 pasal 15, jenis pendidikan Indonesia dibedakan menjadi pendidikan umum, pendidikan kejuruan, pendidikan akademik, pendidikan profesi, pendidikan vokasi, pendidikan keagamaan, dan pendidikan khusus. dan pendidikan profesi (pasal 15 UU RI No. 20 Tahun 2003). Pendidikan kejuruan digunakan untuk istilah pendidikan kejuruan pada tingkat menengah, istilah pendidikan vokasi digunakan untuk pendidikan kejuruan pada tingkat pendidikan tinggi, dan istilah pendidikan profesi digunakan untuk pendidikan kejuruan pada tingkat setelah sarjana (S1). 
Dari beberapa uraian definisi pendidikan kejuruan dan perundang-undangan tersebut di atas dapat disimpulkan bahwa pendidikan kejuruan adalah pendidikan formal tingkat menengah untuk mempersiapkan peserta didik memiliki keterampilan kejuruan tertentu untuk memasuki lapangan kerja dan mengembangkan karirnya setelah bekerja.

\section{Filosofi Pendidikan Kejuruan}

Pendidikan kejuruan harus dikembangkan berdasarkan landasan dan prinsip dasar filsafat kehidupan manusia yang kokoh, yakni untuk mencapai kesejahteraan dan kebahagiaan hidup melalui demokratisasi, menghargai kebebasan individu yang memiliki keunikan masing-masing, dan memberikan bekal praktis yang berguna bagi kehidupannya.

Dalam Undang-Undang No. 20 Tahun 2003 tentang Sistem Pendidikan Nasional Pasal 1 Ayat 1 ditegaskan bahwa pendidikan adalah usaha sadar dan terencana untuk mewujudkan suasana belajar dan proses pembelajaran agar peserta didik secara aktif mengembangkan potensi dirinya untuk memiliki kekuatan spiritual keagamaan, pengendalian diri, kepribadian, kecerdasan, akhlak mulia, serta keterampilan yang diperlukan dirinya, masyarakat, bangsa, dan negara. Dengan kata lain pendidikan memiliki posisi yang strategis dan berdampak secara berantai pada seluruh aspek kehidupan bangsa (UU RI No. 20 Tahun 2003 Tentang Sisdiknas).

Thompson (1973: 91) menyatakan "Every person is important and has dignity, and thus has a right to be educated. Society has responsibility to give every youngster the opportunity to develop to the fullest extent of his capabilities". Pendapat Thomson tersebut sejalan dengan pandangan filsafat eksistensialisme yang menekankan bahwa setiap individu memiliki martabat dan potensi yang unik yang harus dikembangkan melalui pendidikan. Masyarakat memiliki tanggung jawab memberikan pendidikan dan peluang untuk mengembangkan potensinya secara maksimal. Dengan kata lain pendidikan kejuruan harus menumbuhkan potensi peserta didik melalui fasilitas yang memadai, dilaksanakan secara bermartabat, pro perubahan (kreatif, inovative, dan eksperimentatif), menumbuhkan dan mengembangkan bakat, minat, dan kemampuan peserta didik. Jadi pendidikan kejuruan mengutamakan pertumbuhan dan perkembangan peserta didik secara optimal. 
Dewey (1944) sebagai seorang filsuf pragmatis dan pencetus pendidikan progresif di USA, memiliki pandangan bahwa pendidikan harus dapat memberikan kesempatan seluas-luasnya kepada individu untuk berkembang dalam kehidupan masyarakat yang demokratis sesuai dengan kebutuhan individu dan kebutuhan masyarakatnya. (http://www.ilt.columbia.edu/publication/dewey.html). Dengan demikian pendidikan kejuruan harus mampu menawarkan program-program pendidikan yang dibutuhkan oleh setiap individu. Program-program pendidikan kejuruan harus selalu kontekstual terhadap kebutuhan lingkungannya.

\section{Tujuan Pendidikan Kejuruan}

Setiap negara memiliki tujuan pendidikan masing-masing. Thomson (1973:95) menyatakan: "... Vocational education can develop a marketble man by developing his ability to perform skills that extend his utility as tool of production". Pendidikan kejuruan dikembangkan dengan tujuan untuk manusia yang layak jual dengan mengembangkan kemampuannya pada keterampilan kinerja sebagai alat produksi. Finch \& Cruncilton (1984: 12) menyatakan karakteristik pendidikan kejuruan sebagai berikut.

"... these basic characteristic of the vocational and technical curriculum include orientation, justification, focus, in-school success standards, out-of-school success standard, school-community relatinships, federal involvement responsiveness, logistic, and expense”.

Ciri-ciri pokok dari kurikulum pendidikan kejuruan mencakup orientasi, justifikasi, fokus, standar kesuksesan sekolah, standar kesuksesan di luar sekolah, hubungan dengan masayarakat, tanggung jawab negara, logistic, dan biaya.

Indonesia sebagai negara yang sedang berkembang dengan jumlah penduduk yang sangat besar, wilayah yang sangat luas, dan sumberdaya alam yang melimpah memerlukan pembangunan industri di segala bidang seperti bidang pertanian, perikanan, pariwisata, kesehatan, otomotif, informatika, bioteknologi, kimia dan lainnya, sehingga diperlukan tenaga kerja terampil/teknisi lulusan pendidikan kejuruan dalam jumlah yang cukup besar. Jika Indonesia memiliki tenaga terampil yang memiliki kompetensi tinggi, hal tersebut akan menguntungkan bagi industri karena mereka tidak perlu melatih calon tenaga kerja dari tingkat yang paling dasar yang memerlukan investasi biaya tinggi. Dengan demikian, jika pendidikan kejuruan 
mampu menghasilkan tenaga terampil yang berkompetensi tinggi akan menarik tumbuhnya sektor industri yang akan membuka peluang kerja sehingga dapat mengurangi pengangguran secara nasional.

\section{Prinsip-prinsip Pembelajaran Pendidikan Kejuruan}

Camp \& Johnson (2005: 37-49); Wardiman (1998: 83) mengemukakan beberapa prinsip pendidikan kejuruan yang dikembangkan oleh Prosser (1940) yang tercakup dalam "16 Teori Prosser" antara lain: (1) pendidikan kejuruan akan efisien jika disediaan lingkungan belajar sama atau berupa tiruan dari dari lingkungan dimana peserta didik kelak akan bekerja; (2) pendidikan kejuruan yang efektif hanya dapat diberikan jika tugas-tugas di dalam latihan memiliki memiliki kesamaan operasional, yaitu memiliki mesin-mesin yang sama dengan yang akan digunakan dalam bekerja nantinya; (3) pendidikan kejuruan hanya akan efisien jika diajar oleh pendidik atau instruktur yang telah memiliki pengalaman dan berhasil dalam menerapkan keterampilan dan pengetahuan mengenai operasi dan proses kerja yang dilakukan.

Pendidikan pada dasarnya adalah upaya peningkatan produktivitas nasional sesuai dengan prinsip ekonomi human capital investmen. Dengan kata lain upaya peningkatan kualitas manusia menjadi produktif merupakan misi utama pendidikan kejuruan sehingga. Berdasarkan prinsip ini pengeluaran untuk pendidikan tidak dipandang sebagai pengorbanan dan biaya, tetapi sebagi investasi yaitu berkaitan upaya peningkatan pengetahuan dan keterampilan melalui pendidikan dan pelatihan. Cam \& Johnson (2005: 42) menyatakan “... we now believe that human capital theory best serves as the fundamental theoretical premise of contemporary career and technical education".

Dari prinsip Prosser maupun prinsip human capital investment tersebut membawa implikasi agar praktik-praktik pendidikan kejuruan selalu melibatkan industri sehingga dicapai hasil yang efisien. Pendidikan kejuruan memiliki hubungan langsung dengan produktifitas industri, karena dalam pendidikan siswa diajarkan untuk memiliki dan menguasai kompetensi sesuai dengan kebutuhannya. Di sisi lain, pembangunan sekolah kejuruan memerlukan sarana dan prasarana praktikum (investasi) yang lengkap yang modern sesuai dengan kebutuhan riel di lapangan. Prinsip-prinsip pembelajaran kejuruan dilaksanakan praktikum di tempat yang nyata 
merupakan sebuah tuntutan agar proses pendidikan dapat berlangsung efektif dan efisien.

Dari uraian tersebut mengimplikasikan bahwa pendidikan kejuruan merupakan upaya pembentukan kinerja lulusan mencakup pengetahuan, keterampilan, dan sikap setelah siswa menyelesaikan belajarnya dan keterampilan yang dikembangkan sesuai dengan kebutuhan pasar kerja (industri). Dengan demikian, negara berperan untuk melakukan investasi sumberdaya manusia yang pada akhirnya menjadi aset ekonomi dan akan meningkatkan produktivitas baik pribadi, keluarga, maupun nasional.

Pada sisi lain, industri sebagai pengguna lulusan SMK selayaknya juga harus berperan dalam berinvestasi dalam pendidikan SMK melalui partisipasinya dalam pembelajaran di SMK. Melalui kerjasama, industri akan memperoleh keuntungan dalam penyiapan tenaga kerjanya secara ekonomis. Bailey, Hughes, dan Moore (2004: 16) menjelaskan empat keuntungan kerjasama dalam pembelajaran work-based learning antara industri dengan pendidikan vokasi sebagai berikut.

"... that it reinforces and improve academic learning by participant, that it enhances student's work related skills and understanding of careers; that it advances their social and emotional development toward effective adulthood; and that it engage them in new modes of thought seldom found in schools".

Penelitian Harris, Simons dan Moore (2006: 10) pada pelaksanaan Technical and Further Education (TAFE) lembaga yang mengelola pembelajaran pendidikan kejuruan dan pelatihan di Australia dengan model work-based learning menunjukkan hasil kualitas pendidikan meningkat dan kedua belah pihak yakni sekolah dan industri/dunia usaha memperoleh keuntungan dari program kerjasama tersebut (http://www.ncver.edu.au).

\section{Citra Pendidikan Kejuruan}

Kotler (1997: 259) menyatakan bahwa citra merupakan seperangkat keyakinan, ide, kesan, yang dimiliki seseorang terhadap suatu obyek. Buchari Alma (2002: 317) mendefinisikan bahwa citra merupakan kesan yang diperoleh seseorang sesuai dengan pengetahuan dan pengalaman seseorang tentang sesuatu. Menurut Sutisna (2001) citra adalah total persepsi terhadap suatu objek yang dibentuk dengan memproses informasi dari berbagai sumber setiap waktu. Sedangkan Kasali (2003: 28) mendefinisikan citra sebagai kesan yang timbul karena pemahaman akan suatu 
kenyataan. Berdasarkan definisi tersebut menunjukkan bahwa citra merupakan kesan suatu obyek terhadap obyek yang lain yang terbentuk dengan memproses informasi setiap waktu dari sumber informasi yang terpercaya.

Terdapat tiga hal penting di dalam citra yaitu kesan obyek, proses terbentuknya citra, dan sumber terpercaya. Obyek dapat berupa individu, maupun lembaga atau perusahaan yang terdiri dari sekelompok orang di dalamnya. Cira terbentuk dengan memproses informasi, sehingga setiap saat citra akan dapat berubah sesuai dengan informasi yang diterima indvidu atau organisasi. Besarnya kepercayaan obyek terhadap sumber informasi merupakan salah satu dasar penerimaan atau penolakan informasi. Sumber informasi bisa langsung dari perusahaan atau tidak langsung. Dengan demikian citra pendidikan kejuruan adalah kesan seseorang, kelompok (stakeholders) terhadap pendidikan kejuruan yang diperoleh setelah Ia memperoleh informasi dari sumber terpercaya pada waktu tertentu.

Bagi suatu lembaga (perusahaan) citra merupakan bagian yang penting sebagaimana dikemukakan oleh Gronroos (dalam Sutisna, 2001: 332) sebagai berikut: (1) citra positip memberikan kemudahan perusahaan mencapai tujuan sedangkan citra negatip sebaliknya, (2) citra positip memberi perlindungan terhadap kesalahan kecil, kualitas teknis atau fungsional, sedangkan citra negatif memperbesar kesalahan tersebut, (3) sebagai fungsi dari pengalaman dan harapan konsumen atas kualitas layanan perusahaan, dan (4) mempunyai pengaruh terhadap manajemen atau dampak internal, citra yang tidak jelas dan dapat mempengaruhi sikap karyawan terhadap perusahaan (http://oeconomicus.files.wordpress.com/2007/07/citra-perusahaan.pdf).

Pendidikan kejuruan pada dasarnya dapat disamakan dengan perusahaan yang produknya berupa jasa dan layanan (Sallis, 1993; Bush \& Coleman, 2001; Tampubolon, 2005). Dengan demikian Citra tentang mutu produk pendidikan yang berupa jasa layanan menjadi penting untuk disosialisasikan kepada pelanggan pendidikan. Kepala sekolah perlu melakukan program pencitraan utamanya kepada stakeholders pendidikan sehingga mereka dapat membantu pencapaian tujuan pendidikan.

Harison (1995: 71) berpendapat bahwa informasi yang lengkap tentang citra perusahaan mencakup empat hal yaitu: (1) personality, keseluruhan karakteristik 
perusahaan yang dipahami publik sasaran seperti: perusahaan yang dapat dipercaya, memiliki tanggungjawab sosial; (2) reputasi, hal yang telah dilakukan perusahaan dan diyakini berdasarkan pengalaman sendiri maupun pihak lain seperti keamanan transaksi Bank; (3) nilai, budaya perusahaan seperti sikap manajemen yang peduli terhadap pelanggan, tanggap terhadap permintaan maupun keluhan pelanggan; dan (4) identitas perusahaan, yaitu komponen yang mempermudah pengenalan publik sasaran terhadap perusahaan misalnya, logo, warna, slogan. Sedangkan Mohan (2007: 2) mengemukakan lima demensi citra sekolah yaitu :

"The five dimensions of school image which have been taken are: (1) Leadership style of Principal and quality of faculty and academic course, (2) Students' achievement profile - achievement of current students and success of alumni, (3) Infrastructure of school, (4) Parental involvement and cooperation with local community, and (5) Pastoral care of students.

Dari uraian tersebut dapat dikatakan bahwa citra pendidikan kejuruan mencakup (1) keunggulan dan keunikan lulusan dan program pendidikan kejuruan; (2) norma, nilai unggul yang menjadi budaya sekolah diterapkan secara konsisten oleh seluruh komponen sekolah termasuk alumni, dan (3) lingkungan sekolah yang kondusif bagi perkembangan anak didik.

\section{Strategi meningkatkan citra Pendidikan}

Harus diakui bahwa pendidikan kejuruan belum memiliki tingkat citra yang memenuhi harapan. Dengan persoalan-persoalan sebagaimana dipaparkan sebelumnya di atas, pendidikan kejuruan sudah saatnya menyusun strategi yang lebih jelas dan terarah, agar eksistensinya diketahui dan diterima masyarakat sebagaimana mestinya. Sebagai sebuah institusi modern yang 'menjajakan' layanan pendidikan kejuruan perlu mengadopsi atau mengadaptasi konsep komunikasi pemasaran seperti yang telah banyak dilakukan lembaga lainnya. Konsep komunikasi pemasaran bukanlah semata milik organisasi atau lembaga komersial, melainkan juga dapat diterapkan oleh organisasi berbasis nirlaba atau non-profit. Beberapa kalangan menyebutnya sebagai upaya marketing sosial. Nickles (1984) menyatakan komunikasi pemasaran menekankan lima asas penting yakni (1) pemasaran adalah sebuah proses; (2) pemasaran membantu orang dan organisasi memuaskan atau memenuhi kebutuhan mereka; (3) pemasaran melibatkan banyak jenis kegiatan dan fungsi; (4) pemasaran 
melibatkan lembaga-lembaga; dan (5) tujuan pemasaran adalah membangun dan menjaga hubungan satu sama lain (penyedia layanan dan klien/konsumennya).

Mengacu pada kelima prinsip tersebut, pendidikan kejuruan hendaknya melakukan proses pemasaran agar khalayak memperoleh informasi yang benar dan komprehensif tentang peran dan fungsi lembaga pendidikan. Di lain pihak, publik juga dapat dipenuhi, bukan saja kebutuhannya (needs) melainkan juga keinginan (wants) terhadap keberadaaan pendidikan kejuruan berikut layanan yang disediakannya.

Pemasaran adalah penganalisisan, perencanaan, penerapan dan pengawasan program agar terjadi pertukaran nilai dengan pasar yang ditargetkan demi tujuan organisasi. Promosi sebagai bagian dari pemasaran adalah pelayanan mengenalkan seluruh aktivitas yang ada di sekolah agar diketahui oleh khalayak umum. Dengan kata lain promosi sekolah pada dasarnya merupakan forum pertukaran informasi antara organisasi dan konsumen dengan tujuan utama memberikan informasi tentang produk atau jasa yang disediakan oleh sekolah sekaligus membujuk stakeholders untuk bereaksi terhadap produk atau jasa yang ditawarkan. Hasil dari promosi adalah tumbuhnya kesadaran sampai tindakan untuk memanfaatakanya.

Hermawan Kertajaya (2008: 1) menyatakan bahwa inti dari marketing sebenarnya adalah positioning, differentiation, dan brand (PDB). Marketing bukan sekadar marketing-mix atau yang dikenal juga sebagai 4P (product-price-placepromotion). Sebab, marketing-mix tanpa PDB jadinya bersifat komoditas dan me-too saja, bisa dengan mudah ditiru oleh pesaing. Juga bukan segmentation-targetingpositioning (STP) semata, walaupun ini juga penting. Sebab, positioning yang tidak didukung differentiation yang solid akan percuma. Cuma sekadar janji kosong.

Banyak orang yang juga masih salah paham, dikiranya marketing itu identik dengan selling. Karena banyak orang yang pekerjaannya berjualan (selling), tapi di kartu namanya tertera posisi sebagai marketing. Lebih repot lagi ketika orang mulai menganggap bahwa marketing adalah $\mathrm{A} \& \mathrm{P}$ alias advertising and promotion. Orang jadi takut mendengar istilah marketing, karena kuatir akan menghabiskan banyak uang namun hasilnya belum jelas, spend money for nothing.

Hermawan Kertajaya \& Kotler (2005) mengatakan bahwa Marketing itu sebenarnya ada sembilan elemen-yang terdiri dari tiga elemen Strategi, tiga elemen 
Taktik, dan tiga elemen Value —dengan positioning, differensiation, branding (PDB) sebagai intinya.

Tiga elemen strategi adalah segmentation, targeting, dan positioning (STP), dengan positioning sebagai intinya. Tiga elemen taktik adalah differentiation, marketing-mix, dan selling (DMS), dengan differentiation sebagai intinya. Sementara tiga elemen Value adalah brand, service, dan process (BSP), dengan brand sebagai intinya.

Jadi inti strategi marketing dari sebuah perusahaan/ lembaga pendidikan mencakup PDB. Disini pentingnya pimpinan pendidikan kejuruan mampu secara tepat memposisikan produk, merek, keunggulan sekolahnya di benak pelanggan. Kedua, bagaimana kepala sekolah menopang positioning yang tepat ini dengan diferensiasi yang kokoh. Dan ketiga, kalau sudah mampu memposisikan diri secara tepat dan memdukungnya dengan diferensiasi yang kokoh, maka langkah selanjutnya adalah bagaimana membangun brand secara berkelanjutan.

\section{Kepemimpinan dan Pencitraan Pendidikan Kejuruan}

Kepala sekolah merupakan unsur organisasi yang menentukan kefektifan sekolah (Sergiovanni, 1987; Husaini Usman, 2006; Reinhartz \& Beach, 2007). Kepala sekolah memiliki fungsi untuk menetapkan visi, membangun nilai, budaya sekolah, menggerakkan, mengarahkan, memotivasi, dan mengembangkan semua anggota organisasi dan pemangku kepentingan (stakeholders) pendidikan kejuruan untuk memberi dukungan dalam pengembangan kapasitas, kelembagaan, sistem, sumberdaya, budaya dan arahan untuk mencapai tujuan (Blanchard, 2007; Shaw, 2007; Northhous, 2007). Pada sisi lain kepala sekolah juga berperan sebagai manajer yang yang berfungsi menjalankan sistem organisasi mencakup perencanaan, pengorganisasian, komunikasi/memimpin rapat, negosiasi, mengelola konflik, mengelola stress, memasarkan, dan mengevaluasi proses dan produk hasil pendidikan (Blanchard, 2007; Avery, 2006; Reinhartz \& Beach, 2004: 13-15). Dengan demikian upaya untuk memasarkan citra keunggulan sekolah kepada stakeholders pendidikan merupakan tugas dan fungsi kepala sekolah kejuruan. Keberhasilan pencitraan ditentukan oleh kinerja kepala sekolahnya. Depdiknas (2003:25) 
menjelaskan pedoman penilaian kinerja kepala sekolah dengan tiga indikator: (a) kepemimpinan, (b) manajerial, dan (c) kepribadian. Permendiknas No 13 Tahun 2007 tentang standar kepala sekolah menegaskan lima demensi kompetensi kepala sekolah yaitu: kepribadian, manajerial, kewirausahaan, supervisi, dan sosial. Hal tersebut sejalan dengan pandangan Blanchard (2007); Bush \& Coleman (2004); Suyanto (2006); Northouse (2007); Zenger (2004) bahwa untuk memberdayakan stakelholders seorang pemimpin perlu menerapkan kepemimpinan transformasional yang bersumber pada, kekuatan visi misi, inspirasi, motivasi, dan pemberdayaan seluruh stakeholders organisasi.

Dari uraian tersebut dapat disimpulkan bahwa keberhasilan program pencitraan sekolah ditentukan oleh kepemimpinan kepala sekolah yang memberdayakan semua potensi organisasi.

\section{Manfaat Pencitraan Pendidikan Kejuruan}

Keberhasilan pencitraan bagi suatu organisasi akan meningkatkan kepercayaan, keyakinan, dukungan, minat dan animo masyarakat masyarakat terhadap pendidikan kejuruan. Prasetijo dan Ilahauw (2005) menyatakan bahwa konsumenlah yang akan menggunakan produk/jasa suatu perusahaan. Oleh karena itu memahami perilaku konsumen stakeholders untuk menggunakan produk tersebut perlu ditingkatkan. Menurut Prasetijo \& Ihalauw (2005:13) konsumen akan mengambil keputusan untuk menggunakan produk dengan menggunakan sumber-sumber yang tersedia yaitu waktu, uang, upaya, untuk ditukar dengan barang untuk dikonsumsi. Oleh karena itu semua faktor baik internal maupun eksternal yang mempengaruhi seseorang dalam membuat keputusan beli (menggunakan produk) harus dipertimbangkan. Dengan demikian Stakeholders pendidikan kejuruan akan terdorong untuk mendukung program pembelajaran, menggunakan lulusan, atau berpartisipasi aktif menunjang pendidikan kejuruan jika mereka memperoleh manfaat dari dukungan dan partisipasi tersebut.

Prasetijo dan Ihalauw (2005: 17) menggambarkan faktor-faktor yang menentukan seseorang untuk menggunakan produk antara lain: (1) pengaruh internal mencakup kebutuhan, motivasi, kepribadian, psikografik, persepsi, pembelajaran, dan sikap; (2) kondisi konsumen mencakup: kebutuhan, sikap, persepsi, gaya hidup; (3) 
pengaruh eksternal mencakup: keluarga, kelas sosial, budaya dan sub budaya, kelompok acuan, dan komunikasi pesanan.

Dengan demikian dalam kontek pendidikan kejuruan atau kontek sekolah, maka kepala sekolah harus mampu menciptakan prinsip marketing dengan menawarkan keunggulan sekolah sebagai posisionong, budaya sekolah sebagai nilai yang dijual (brand) dan keunikan program atau mutu lulusan yang memiliki defferensiasi dibandingkan dengan sekolah yang lain.

Kerangka konseptual pentingnya pencitraan dan manfaat bagi perbaikan mutu input dan output sekolah digambarkan pada Gambar 1.

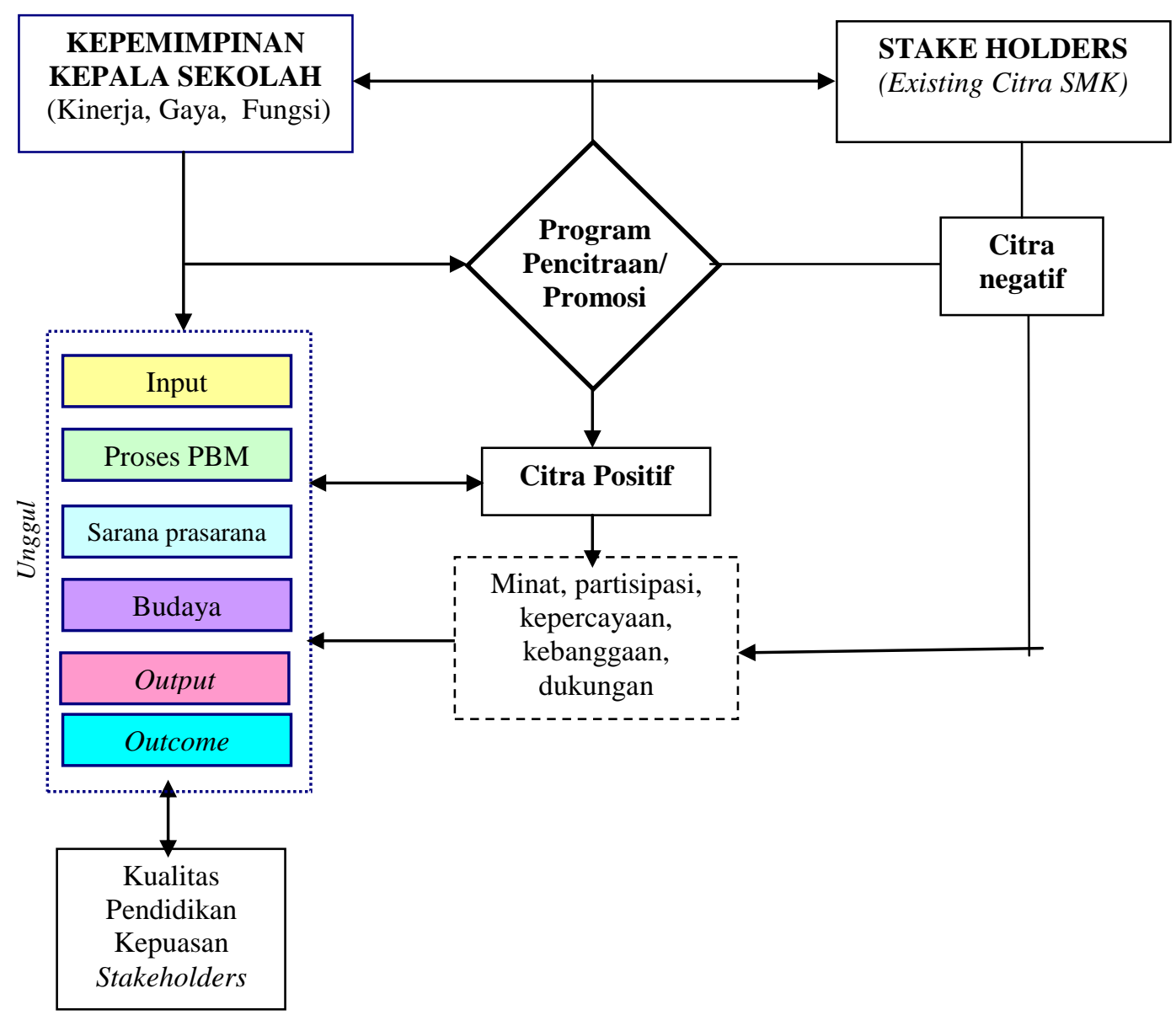

Gambar 1. Kerangka Konseptual Pentingnya Pencitraan Bagi Sekolah

\section{Penelitian-penelitian yang relevan}

Pimpa, N. \& Suwannapirom (2007: 99-107): melaporkan lima alasan siswa memilih SMK "... five key influencing factors: personal attitude, curriculum, potential employment, attractiveness of campus, and tuition fees" . Selanjutnya ditemukan pula 
bahwa guru SMP dan orang tua memiliki pengaruh yang kuat pada siswa untuk memilih SMK. Husaini Usman (2000: 14) menemukan fakta bahwa pengembangan sekolah seutuhnya di SMK mengalami kegagalan karena kepala sekolahnya cenderung menerapkan gaya kepemimpinan otoriter bukan menampilkan entrepreneur. Husaini Usman (2000: 15) profil entrepreneur Kepala SMK belum menunjang visi dan misi SMK. Catri \& Barrick (1996: 26) melakukan penelitian dengan tema: Marketing and marketing effectiveness perceptions of ohio vocational education planning district (VEPD) superintendents melaporkan perlunya marketing bagi pendidikan vokasi. Kuatnya promosi diorientasikan pada technical assistance, inservice training, dan kualitas strategi perencanaan materi pemasaran dan perbaikan keefektifannya.

Stone (1993: 26) meneliti dengan judul: Debunking the Myth, research offer ammunition to fight misperception of vocational education menyimpulkan bahwa terdapat misperception masyarakat terhadap pendidikan kejuruan dan harus dilawan dengan hasil penelitian_(http://www.proquet.com/pqdweb). Paryono (2006: 1) meneliti dengan tema penelitian "Perceived image of vocational and technical education and improvement initiative" memperoleh temuan antara lain bahwa pendidikan kejuruan di Asean masih mendapatkan stigma negatif (http://www.voced.edu.au/td/tnc/92.220);

Dengan demikian dapat disimpulkan bahwa penelitian tersebut berimplikasi bagi kepemimpinan pendidikan kejuruan untuk melakukan program-program pencitraan keunggulan pendidikan kejuruan bagi siswa SMP khususnya dan stakeholders pada umunya.

\section{Best Practice Pencitraan Sekolah menengah Kejuruan.}

SMK PGRI 3 Malang yang terletak di Jalan Raya Tlogomas Malang adalah salah satu SMK Swasta di Kota Malang yang berhasil memperoleh kepercayaan tinggi dari masayarakat dan industri. Jumlah siswa yang direkrut setiap tahun lebih dari 1000 siswa, jumlah lulusan yang direkrut industri sebelum lulus setiap tahun 25$40 \%$ (Statistik, SMK PGRI 3 Malang Tahun 2009). Tingginya pemahaman pimpinan dan warga SMK PGRI 3 terhadap pentingnya mutu pembelajaran dan etos kerja lulusan sebagai esensi citra sekolah terus disosialisaikan melalui program pencitraan yang kuat. Berdasarkan wawancara dengan kepala sekolah SMK PGRI 3 Malang 
disimpulkan bahwa manajemen sekolah berbasis kualitas (Quality based Education) merupakan dasar efektifitas dari segala keberhasilan program-program sekolah.

Pendidikan yang bermutu merupakan standar kesesuaian performance terhadap atribut-atribut yang dianggap penting oleh para pelanggan/pengguna jasa pendidikan. Atribut-atribut mutu tersebut hendaknya diketahui oleh penyelenggara sekolah sehingga dalam operasionalisasi kegiatan dapat mengacu pada kepentingan mutu pelanggan. Kegiatan pendidikan di sekolah sebagai salah satu bentuk pelayanan jasa memiliki bentuk proses yang sirkuler bukan linier atau sekedar jual beli. Dalam sistem pendidikan, sekolah hendaknya dapat memberikan inisiatif peran yang dapat memancing peran positif komponen sistem pendidikan lainnya .

\section{a. Strategi Pengelolaan Sekolah}

Masyarakat mengharapkan sekolah dapat memberikan penyediaan pelayanan pendidikan secara maksimal. Harapan yang besar pada sekolah memerlukan energi yang besar. Untuk itu diperlukan banyak dukungan dari berbagai pihak. Sekolah dalam menjalankan kegiatan pendidikan sangat tergantung kepada tiga jenis sumber pemasukan keuangan, yaitu: (1) negara, (2) masyarakat pengguna lulusan, dan (3) orang tua siswa. Masalah yang sering timbul adalah bagaimana jaminan ketersediaan dana tersebut secara jelas dan kontinyu, tanpa mengganggu kelangsungan kegiatan operasional sekolah.

Dalam kondisi tertentu, sekolah melakukan strategi alliances untuk meningkatkan kapasitas dan kualitas pelayanan. Stategi alliance merupakan bentuk kerjasama dengan lembaga lain yang paling aman dijalankan dibandingkan metode kerjasama lainnya (piggy backing dan merger), ketika identitas organisasi tersebut masih terjaga. Hal ini sangat logis ketika kompetensi dan kolaborasi antar lembaga pendidikan akan menjadi semakin dinamis, maka untuk materi-materi tertentu (seperti ketrampilan dan seni), sekolah dapat bekerjasama dengan mitra yang kompeten. Sebagai contoh untuk penyediaan pendidikan ketrampilan pada kasus SMK PGRI 3 Malang sekolah menggandeng berbagai industri (1) PT Oracle Indonesia, (2) PT Indonesia Power, (3) PT Suzuki Indomobil, (4) PT PAL, (5) PT Morodadi (karoseri), (6) PT Sharp, (7) LG Indonesia, dan (8) PT Indomart untuk menyelenggarakan kelas industri. Perlu diperhatikan bahwa strategi ini memiliki konsekuensi terpengaruhnya 
citra sekolah oleh lembaga mitra. Untuk itu diperlukan penetapan mitra yang memiliki visi dan misi yang sejalan serta reputasi yang baik.

Pola persaingan antar sekolah dapat disikapi sebagai suatu iklim yang kondusif dalam pertumbuhan penyelenggaraan pendidikan. Isu-isu komersialisasi pendidikan merupakan konsekuensi logis dari tidak meratanya pasar yang terlayani oleh sekolah yang ada. Timbulnya sekolah favorit adalah akibat atribut-atribut sekolah yang secara panca indra tertangkap sebagai sekolah yang dapat memenuhi kebutuhan pasar. Atribut-aribut sekolah antara lain visi dan misi, sarana prasarana fisik, reputasi pendidik, prestasi siswa dan lulusan. Di lain pihak perlu pengelompokan pasar pengguna jasa pendidikan yang luas ke dalam beberapa segmen. Sekolah dapat lebih menajamkan strategi pengelolaan sehubungan dengan pasar yang menjadi segemennya. Akan lebih baik sekolah menjadi yang terbaik di kelasnya.

\section{b. Manajemen Pemasaran Sekolah}

Sekolah hendaknya dapat berorientasi kepada kepuasan pelanggan. Selain itu juga perlu mencermati pergeseran konsep 'keuntungan pelanggan' menuju 'nilai' (value) dari jasa yang dihasilkan. Sekolah mahal tidak menjadi masalah sepanjang manfaat yang dirasakan siswa melebihi biaya yang dikeluarkan. Dan sebaliknya sekolah murah bukan jaminan akan diserbu calon siswa apabila dirasan nilainya rendah. Langkah-langkah kegiatan dalam mengelola pemasaran sekolah yaitu:. (1) identifikasi pasar, (2) segmentasi pasar dan positioning, (3) diferensiasi produk, dan (4) komunikasi pemasaran.

Tahapan pertama dalam pemasaran sekolah adalah mengidentifikasi dan menganalisis pasar. Dalam tahapan ini perlu dilakukan suatu penelitian/ riset pasar untuk mengetahui kondisi dan ekspektasi pasar termasuk atribut-atribut pendidikan yang menjadi kepentingan konsumen pendidikan. Termasuk dalam tahapan ini adalah pemetan dari sekolah lain.

Langkah kedua adalah segmentasi pasar dan positioning, penentuan target pasar merupakan langkah selanjutnya dalam pengelolaan masalah pemasaran sekolah. Dalam pasar yang sangat beragam karakternya, perlu ditentukan atribut-atribut apa yang menjadi kepentingan utama bagi pengguna pedidikan. Secara umum pasar dapat dipilah berdasarkan karakteristik demografi, geografi, psikografi maupun perilaku. 
Dengan demikian sekolah akan lebih mudah menentukan strategi pemasaran sehubungan dengan karakteristik dan kebutuhan pasar. Setelah kita mengetahui karakter pasar, maka kita akan menentukan bagian pasar mana yang akan kita layani. Tentunya secara ekonomis, melayani pasar yang besar akan membawa sekolah masuk ke dalam skala operasi yang baik.

Langkah ketiga adalah diferensiasi produk, dengan cara yang efektif dalam mencari perhatian pasar. Dari banyaknya sekolah yang ada, orangtua siswa akan kesulitan untuk memilih sekolah anaknya dikarenakan atribut-atribut kepentingan antar sekolah semakin standar. Sekolah hendaknya dapat memberikan tekanan yang berbeda dari sekolah lainnya dalam bentuk-bentuk kemasan yang menarik seperti logo dan slogan. Fasilitas internet mungkin akan menjadi standar, namun jaminan internet yang aman dan bersih akan menarik perhatian orangtua. Melakukan pembedaan secara mudah dapat pula dilakukan melalui bentukbentuk tampilan fisik yang tertangkap panca indra yang memberikan kesan baik, seperti pemakaian seragam yang menarik, gedung sekolah yang bersih atau stiker sekolah.

Langkah keempat adalah komunikasi pemasaran, yakni sebagai lembaga ilmiah akan lebih elegan apabila bentuk-bentuk komunikasi disajikan dalam bentuk/ format ilmiah, seperti menyelenggarakan kompetisi bidang studi, forum ilmiah/ seminar dan yang paling efektif adalah publikasi prestasi oleh media independen seperti berita dalam media massa. Komunikasi yang sengaja dilakukan sekolah dalam bentuk promosi atau bahkan iklan sekalipun perlu menjadi pertimbangan. Bentuk dan materi pesan agar dapat dikemas secara elegan namun menarik perhatian agar sekolah tetap dalam imej sekolah sebagai pembentuk karakter dan nilai yang baik.

Publikasi yang sering terlupakan namun memiliki pengaruh yang kuat adalah promosi "mouth to mouth". Alumni yang sukses dapat membagi pengalaman (testimony) atau bukti keberhasilan sekolah. Dengan langkah-langkah kegiatan tersebut diatas maka sekolah dapat mencapai keseimbangan dalam operasionalisasi pengajaran dalam kondisi memperebutkan 'kue' dari banyak penyelenggara sekolah. Dengan demikian masalah sekolah yang kekurangan murid tidak terjadi lagi.

Sekolah hendaknya memiliki sistem pengelolaan/manajemen yang dapat memaksimalkan atribut-atribut yang dianggap pasar sebagai atribut yang penting 
dalam sebuah institusi pendidikan. Sehingga konsep pemasaran pedidikan yang berwawasan jasa/produk pelayanan akan berkembang menjadi konsep pemasaran pendidikan yang berorientasi pasar bahkan berwawasan masyarakat.

\section{KESIMPULAN}

Berdasarkan pembahasan dan kajian tersebut di atas disimpulkan hal-hal sebagai berikut : Citra merupakan bagian yang penting bagi pendidikan kejuruan, Citra pendidikan berupa keunggulan merek (brand) sekolah mencakup keunggulan input, proses, output, outcome, dan sarana prasarana pembelajaran, serta keunggulan budaya sekolah, Untuk meningkatkan pencitraan sekolah kepala sekolah kejuruan perlu melakukan marketing sekolah mencakup posisioning, differensiasi, dan branding keuggulan dan keunikan sekolah kepada stakeholders, Citra positif yang terbentuk melalui marketing akan memberikan keuntungan kepada sekolah berupa: meningkatnya minat, meningkatnya dukungan, bertambahnya keyakinan dan kepercayaan masayarakat pada sekolah,

Implikasi dari kondisi riel citra pendidikan kejuruan yang masih kurang baik serta tuntutan untuk memperbaiki citra pendidikan adalah pertama, kepala sekolah perlu melakukan pencitraan secara intensif dan inovatif agar eksternal stakeholders memiliki pandangan yang berubah menjadi baik bagi pendidikan kejuruan. Karena materi pencitraan pada adasarnya adalah marketing keungulan produk yang mencakup potitioning, differensiasi, dan branding sekolah, maka kepala sekolah harus berani melakukan perubahan visi dan misi sekolah untuk fokus pada perbaikan keunggulan lulusan (output dan out come) dan membangun budaya sekolah yang berbeda dengan sekolah lainnya.

\section{DAFTAR PUSTAKA}

Anonymous (2005). A-levels are not the only route. ProQuest Education Journal Education and Training, 47, 6/7 pg. 460. Diambil tanggal 18 Agustus 2008 dari http://www.proquest.com/ pqdweb.

Bishop, J. H. (1989). Making vocational education more effective for at-risk youth [Electronic version]. Vocational Education Journal, 64(4), 14-19. Diambil pada tanggal 9 Agustus 2008 dari http://digitalcommons.ilr.cornell.edu.

Catri, D. B. (1998). Vocational education's image for the $21^{\text {st }}$ Century. Eric educational report. Diambil pada tanggal 18 Agustus 2008 dari. http://findarticles.com org/1999-2/21st.htm. 
Harris, R., Simons, M., \& Moore, J. (2005). A huge learning curve TAFE practitioners ways of working with private enterprises. Diambil 15 Mei 2008 dari http://www.ncver.edu.au.

Husaini Usman. (2000). Paradigma baru peran administrasi pendidikan dalam peningkatan kualitas sumberdaya manusia menuju indonesia baru. Pidato Pengukuhan Guru Besar UNY, Sabtu 22 Juli 2000. Yogyakarta: Universitas Negeri Yogyakarta.

Hermawan Kertajaya. (2008). PDB is positioning, differentiation and brand. Diambil pada tanggal 2 Desember 2008 dari http://www.kompas.com/read/xml/ 2008/10/18/10113478/pdb.is.positioning.differentiation.and.brand.

Kotler, P. \& Fox, K. F. (1985). Strategic marketing for educational institutions. Englewood Cliffs, NJ: Prentice-Hall, Inc.

Kotler, P. (2000). Marketing management, $10^{\text {th }}$ edition. Upper Saddle River:Prentice Hall, Inc.

Nickels, G. W. (1984). Marketing communication and promotion". Text and cases, $3^{\text {rd }}$ edition. USA: John Willey and Sons.

Northous, P. W. (2007). Leadership theory and practice. foruth edition. Thousand Oaks: Sage Publication.

Paryono (2006). Perceived image of vocational and technical education and improvement initiative. diambil pada tanggal 8 Agustus 2008 dari http://www.voced.edu.au/td/tnc/92.220.

Pimpa, N. \& Suwannapirom (2007). Thai students' choices of vocational education: marketing factors and reference groups . Education Reasearch for Policy Practice Journal. (7) (2) p.99-107

Perkins, D. C. (1998). The Carl D. Perkins vocational and technical education act, Public Law 105-332. USA: US Department of Education. Diambil 18 Agustus 2008 dari http://www.ed.gov/offices/OVAE/CTE/perkins.htm.03-08.

Reinhartz, J. \& Beach, D. M. (2004). Educational leadership changing school chancngingroles. Boston: Pearson.

Robbins, P. S. (1994).Teori Organisasi; Struktur, Desain \& Aplikasi. Arcan.

Thomson, F. J. (1973). Foundation of vocational education. Social and philosophical concept. New Jersey: Englewood cliffs.

Undang-undang Republik Indonesia No 20 Tahun 2003 Tentang Sistem Pendidikan Nasional .

Wardiman, D. (1998). Pengembangan sumber daya manusia indonesai melalui sekolah menengah kejuruan. Jakarta: Jayakarta Agung Ofset. 